Article

\title{
Evaluating the Thermal Pollution Caused by Wastewaters Discharged from a Chain of Coal-Fired Power Plants along a River
}

\author{
Marc A. Rosen ${ }^{1, \dagger, *}$, Cornelia A. Bulucea ${ }^{2, \dagger}$, Nikos E. Mastorakis ${ }^{3,4, \dagger}$, Carmen A. Bulucea ${ }^{5, \dagger}$, \\ Andreea C. Jeles ${ }^{6, \dagger}$ and Constantin C. Brindusa ${ }^{7, \dagger}$ \\ 1 Faculty of Engineering and Applied Science, University of Ontario Institute of Technology, \\ Oshawa, ON L1H 7K4, Canada \\ 2 Faculty of Electrical Engineering, University of Craiova, Craiova 200440, Romania; \\ E-Mail: abulucea@em.ucv.ro \\ 3 Industrial Engineering Department, Technical University of Sofia, 8 Str. Kliment Ohridski \\ Boulevard, Sofia 1756, Bulgaria; E-Mail: mastor@tu-sofia.bg \\ 4 Hellenic Naval Academy, Military Institutions of University Education (ASEI), \\ Piraeus 18539, Greece; E-Mail: mastor@hna.gr \\ 5 Faculty of Medicine, University of Medicine and Pharmacy of Craiova, Craiova 200349, Romania; \\ E-Mail: carmen.bulucea@umfcv.ro \\ 6 Department of Tourism and Public Food, Technical College of Arts and Crafts "Constantin \\ Brancusi” of Craiova, Craiova 200135, Romania; E-Mail: andreee_83@yahoo.com \\ 7 Faculty of Engineering, University Constantin Brancusi of Targu Jiu, Targu Jiu 210135, Romania; \\ E-Mail: rinstalctin@yahoo.com \\ $\dagger$ These authors contributed equally to this work. \\ * Author to whom correspondence should be addressed: E-Mail: marc.rosen@uoit.ca; \\ Tel.: +1-905-721-8668.
}

Academic Editor: Francesco Asdrubali

Received: 28 March 2015 / Accepted: 8 May 2015 / Published: 13 May 2015

\begin{abstract}
Reliable and safe operation of a coal-fired power plant is strongly linked to freshwater resources, and environmental problems related to water sources and wastewater discharge are challenges for power station operation. In this study, an evaluation on the basis of a wastewater thermal pollution vector is reported for the environmental impact of residual water generated and discharged in the Jiu River during the operation of thermoelectric units of the Rovinari, Turceni and Craiova coal-fired power plants in
\end{abstract}


Romania. Wastewater thermal pollutant vector Plane Projection is applied for assessing the water temperature evolution in the water flow lane created downstream of each power plant wastewater outlet channel. Simulation on the basis of an Electricity of France model, and testing validation of the results for thermoelectric units of $330 \mathrm{MW}$ of these power plants are presented.

Keywords: coal-fired power plant; environmental impact; thermal pollution; wastewater pollutant vector

\section{Introduction}

Within an industrial ecology framework, an estimation of the industrial metabolism should explore not only economic and social issues and benefits, but also the environmental impacts [1-3]. Coal-fired power plants often represent one of the larger contributors to acid rain of industrial activity, since they are a large source of sulfur oxides. The coal-fired sector is also a significant source of nitrogen oxides, with an impact comparable to that of transportation [4-8].

Beyond the environmental and human health impacts caused by the air pollutant emissions generated by coal-fired power plant operation, other environmental issues exist, including those related to water resources and thermal pollutant wastewater generation [9-18].

Thermoelectric power plants are one of the main causes of thermal pollution. Thermal pollution is defined as the degradation of water quality by any process that changes ambient water temperature [11-13]. A common cause of thermal pollution is the use of water as a coolant by thermoelectric generation stations, particularly coal-fired power plants. Water withdrawals for thermoelectric power generation have been shown to be the highest of any industry [4-8,14-20], and most of that water is used in cooling systems.

Thermoelectric power generation in a coal-fired plant consists of the conversion of thermal energy to electrical energy $[5,8,12]$. Coal often is the fuel used to heat a liquid to produce a high-pressure vapor (usually water is heated to produce steam) which then is expanded in a turbine that drives an electric generator $[5,8,12]$. An important step in this process is the change of phase of the vapor to a liquid following the turbine stage, and this is where the requirement for cooling water arises. A vacuum is created in the condenser, which also creates a vacuum at the exit of the turbine; this low pressure is important for the thermodynamic efficiency of the process. The water requirement in coal-fired power plants is mainly as cooling water for condensing steam in a condenser, typically having a shell-and-tube heat exchanger. The operating parameters of the cooling system affect the overall power generated.

Over the last several decades, the thermal wastewater of a power plant cooling system discharged in a river or lake has been demonstrated to represent a potential environmental impact. By the middle of 1960s, there were many research projects concentrating on thermal discharges in the UK, the United States and Europe, and the term "thermal pollution" was coined [9-12]. From 1960-1970, the literature [9-12] concerned with pollution by heat grew consistently, with many major publications focusing on the environmental impact of power plant thermal discharges. Still, since the late 1970s, the 
number of publications declined, though the amount of heat discharged from power stations in rivers and lakes continued to increase [9-12], despite the prediction for increased construction of power stations worldwide. It may be that, for a long time, predictions of the ecological consequences of thermal discharges have been too simplistic and the constraints wrongly targeted because of the lack of understanding by ecologists of the demands of the electricity industry and the subsequent effects on the operation of cooling water supply systems of power stations, and of thermal wastewater discharges [9-12,15-21].

In essence, thermoelectric power plants boil water to produce steam, and utilize very large volumes of water from nearby rivers, lakes and oceans to cool the steam and convert is back to a liquid so it can be used to produce more electricity. Consequently, the fresh water from a river, for instance, used in the power plant coolant system is returned to the natural environment at a higher temperature. This entire cooling process can have environmental consequences, since this change in temperature of the river water decreases the oxygen supply and affects aquatic ecosystems. It has been shown that the use of once-through cooling systems causes significant environmental impacts, killing billions of fish, degrading aquatic ecosystems, and increasing the temperature (usually locally) of rivers, lakes, and ocean waters [14-21]. It is difficult to define the limits of a thermal discharge effect in an ecological context [9]. Nonetheless, nowadays it is generally accepted that the initial rise in temperature of the receiving water (river or lake) at the outlet point of the thermal discharge should be less than $5{ }^{\circ} \mathrm{C}$, in order to avoid impact on aquatic ecosystems [9-12,16-20].

To better understand and manage this problem, reliable information about the evolution of the temperature of waters discharged from coal-fired power plants is needed. The objective of this study is to address this issue by predicting the temperatures.

\section{Case Study: Wastewaters from a Chain of Thermoelectric Power Plants along Jiu River}

As is widely known, reliable and safe operation of a coal-fired power plant is linked to freshwater resources [8,10,15-19]. Despite the worldwide pressure to retire existing coal-fired power plants and deny permits for new ones, the continuously increasing demand for electricity makes it likely that humankind will not discontinue the use of coal-fired power plants in the near future. However, thermoelectric generation requires a sustainable and large freshwater source, mainly to cool and condense the steam after it exits the turbine. Consequently, the thermoelectric plant operation causes industrial wastewater to be discharged into the water source, often a local river.

The wastewater discharged into the water source depends on the type of cooling system of the thermoelectric unit. The three basic types of cooling systems exist [8,10,15], namely once-through (or open-cycle), closed-cycle and dry cooling. They differ very much in their water usage, with once-through cooling system needing the freshest water and being the most environmentally harmful [15-22].

In this study, we take into consideration a chain of three thermoelectric power plants of Romania, namely Rovinari, Turceni and Craiova, situated along Jiu River, into which they are discharging wastewaters (see Figure 1). 


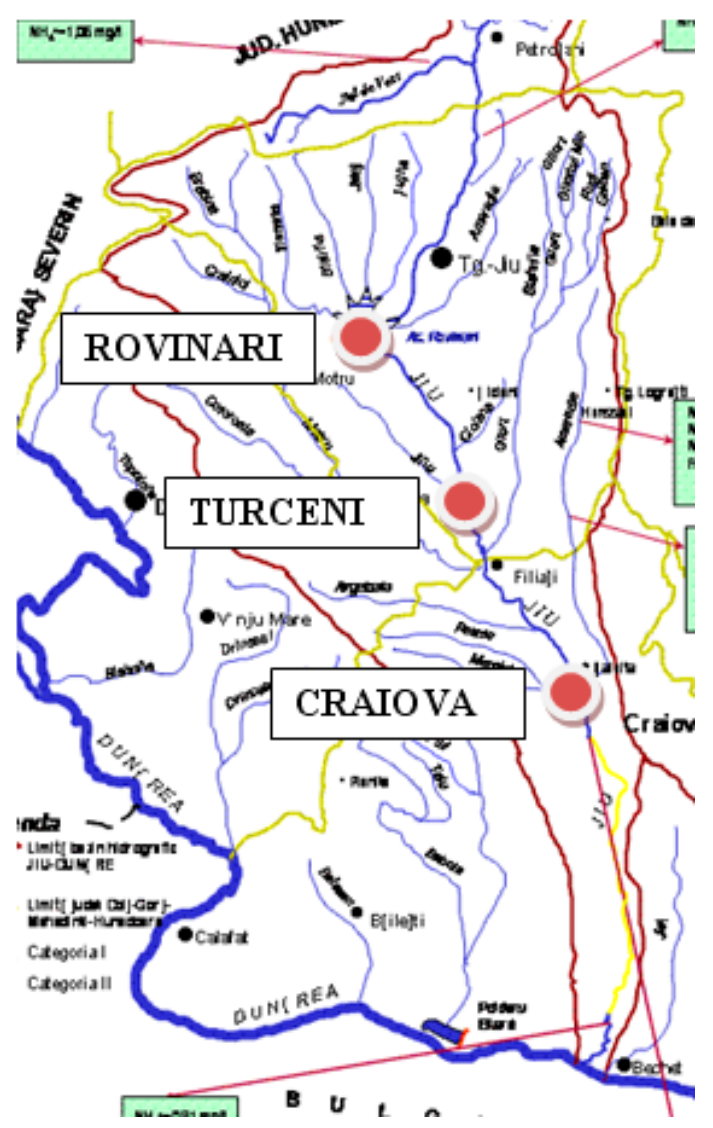

Figure 1. Location of Rovinari, Turceni and Craiova thermoelectric power plants along Jiu River in Romania.

The thermoelectric units of the Rovinari, Turceni and Craiova power plants are equipped with a water recirculating system using wet cooling towers in order to dissipate heat from the cooling water to the atmosphere. In this wet recirculating system, the warmed cooling water is pumped from the steam condenser to the cooling towers. However, for economic reasons the power stations are operating as open systems (once-through systems), meaning without recirculation of the water in the cooling system of the power plant. In other words, the necessary fresh water is provided from the river and the wastewater is discharged back to the same river, without using the cooling towers of the power plants.

Taking into consideration the case of three power stations connected in a cascading fashion from the viewpoint of the cooling systems, the wastewaters discharged in the same river could represent a significant environmental impact, concerning aquatic ecosystems in the river. In line with this idea, this paper deals with the assessment of temperature evolution in the river water downstream of the outlet, caused by a warm water discharge. This study reports an evaluation, on the basis of a wastewater thermal pollutant vector, of the environmental impact of wastewater discharged from a chain of power stations into a single river. The wastewater is the spent water used to operate the cooling systems of the power stations.

\section{Wastewater Thermal Pollutant Vector of a Chain of Coal-Fired Power Plants along Jiu River}

The environmental thermal pollutant vector of wastewaters discharged from Rovinari, Turceni and Craiova coal-fired power plants of Romania are analyzed here. These power stations receive 
freshwater from and discharge wastewater into the Jiu River [23]. From the viewpoint of the cooling systems, these power plants are connected in a cascading fashion.

The waters supplied to the thermoelectric units of these power plants are surface waters with a varying temperature (usually in the range $0-30{ }^{\circ} \mathrm{C}$ ). The pollutant emission source for this river caused by these industrial facilities is mainly associated with the wastewater discharging process. Both the supply of freshwater and the discharge of wastewater are performed through the culvert channels provided with special inlets and outlets, respectively. These surface channels are comprised of concrete and embankment (see Figures 2 and 3), with a slope of 1\% to ensure a minimum water flow without destabilizing the optimum level of the natural pond. Figure 2 illustrates the process water culvert channel for the water inlet of the river Jiu. Figure 3 shows the technical platform on which is fixed the ultrasonic level sensor. That is the location of the inlet pipe for the test water to be treated in the monitoring cabin, presented in Figure 4.

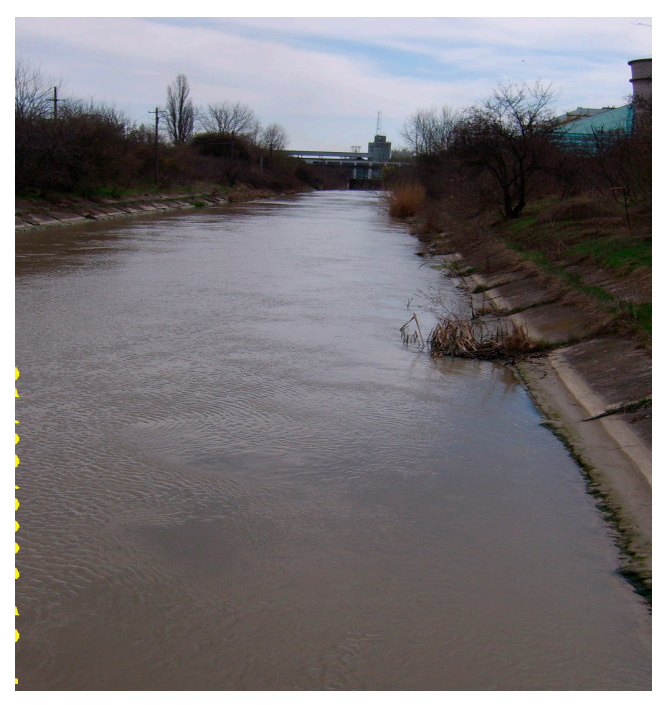

Figure 2. Longitudinal view of the supply channel.

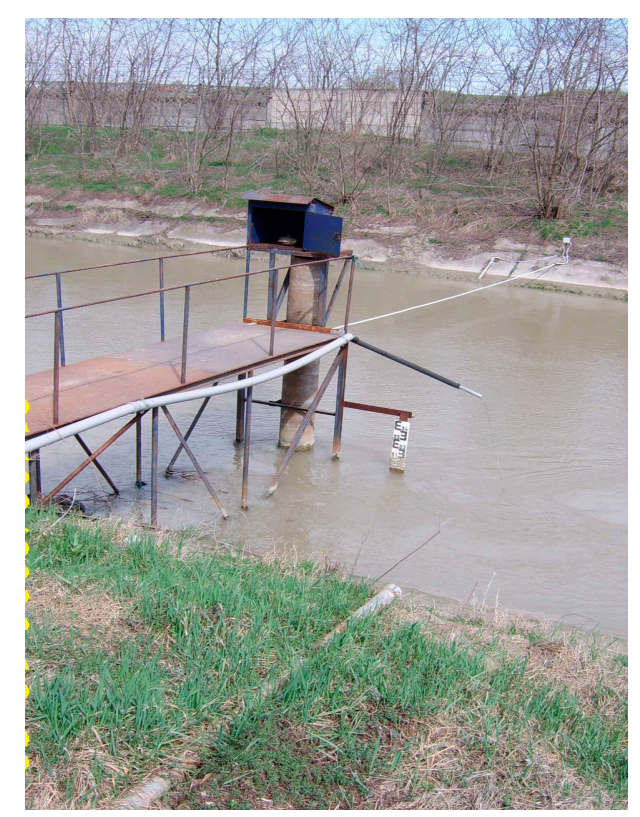

Figure 3. Experimental platform for supply channel. 

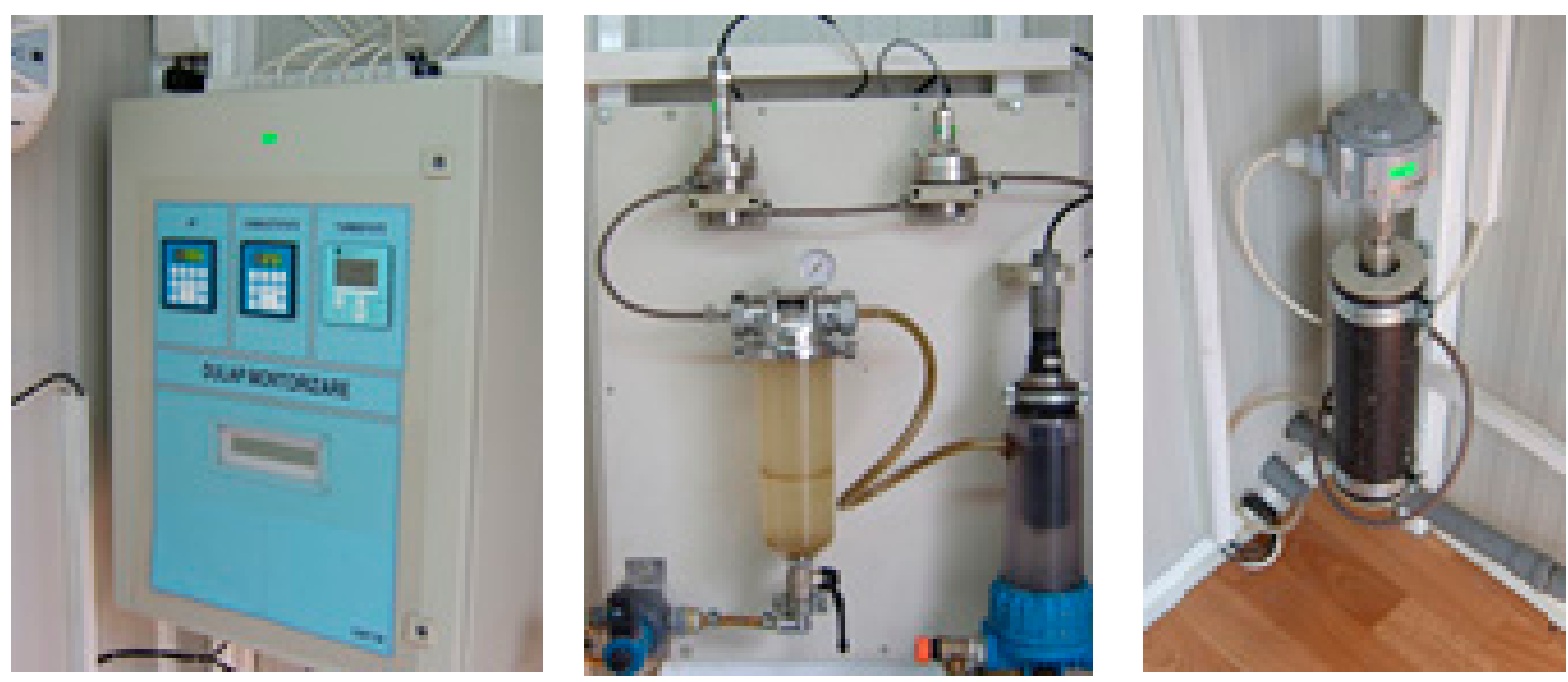

Figure 4. Monitoring cabin.

The water flow supplied by the Jiu River to these power plants is provided through high capacity pumps and by modifying the upstream dam inlet level. Figure 4 shows the thermostatic and secured cabin for monitoring necessary water parameters, i.e., $\mathrm{pH}$, conductivity, suspensions. The physiochemical parameters are routinely checked, in real time, through complex equipment installed in a monitoring cabin (Figure 4), with a telemetric transmission of the collected data. This way, in the first stage, the following freshwater parameters are determined: conductivity, $\mathrm{pH}$, temperature, water level in the channel, water flow rate, and inlet water flow. The physiochemical parameters of freshwater provided through the supply channel are valuated with the measuring transducers.

Furthermore, water treatment in the Chemical Section is performed to provide the demineralized water necessary for steam production and the softened water to be added in the district heating network.

Water pretreatment is necessary to reduce the suspension in the raw water, using several decanters operating on the basis of coagulation and flocculation processes. Inside the decanters, a decarbonation process also occurs, by treatment with $\mathrm{Ca}(\mathrm{OH})_{2}$ in order to obtain a precipitation of $\mathrm{Ca}$ and $\mathrm{Mg}$ soluble salts. Decanted water is stored in tanks, and through a pump system is provided to the demineralized water and softened water installations.

The installation for water demineralizing is necessary to produce an appropriate water for steam production. Water demineralization is carried out through the six units of ionic filters.

The water softening installation provides the softened water to be added to the district heating network.

\subsection{Discharged Wastewater Pollutant Vector}

The thermoelectric units of the Rovinari, Turceni and Craiova power plants are equipped with a water recirculating system using wet cooling towers in order to dissipate the heat from the cooling water to the atmosphere. In this wet recirculating system, the warmed cooling water is pumped from the steam condenser to the cooling towers $[2,8,19,23]$.

The pollutant vector of discharged wastewater $\left(\vec{V}_{D W W}\right)$ is completely specified (from a strictly vectorial viewpoint) by: direction, sense, magnitude, origin and head-arrow. 
The vector direction is defined by the wastewater discharging channel that links the power plant with the river via an ecological wastewater treatment station [23-32]. The vector sense is defined by the wastewater flowing sense. The vector magnitude is related to the wastewater velocity that must be at minimum $1.5 \mathrm{~m} / \mathrm{s}$ in order to avoid suspension sedimentation on the discharging channel bottom. The origin of the vector is at the power plant inlet location while the vector head-arrow is at the discharging channel outlet.

The physiochemical parameters of water that can be measured are: temperature, conductivity, particulate matter in suspension, water fixed residue, and $\mathrm{pH}$ value. Determination of $\mathrm{pH}$ value is necessary to establish the acidic or alkaline nature of the water. Electrometric measurement is a precise method, and the pH-meter has small dimensions and is mobile. Water acidity is associated with the presence of free carbon dioxide, mineral acids and salts of strong acids with weak alkalis. Water alkalinity is associated with the presence of alkaline carbonates, bicarbonates, and hydroxides. This study focuses on the wastewater thermal pollution evaluation.

\subsection{Wastewater Thermal Pollutant Vector Plane Projection}

The Plane Projection (PP) of wastewater thermal pollutant vector allows for the temperature evaluation in the water flow lane created at certain distances in the river from the wastewater outlet channel. This study deals with long distances (in the range of 1-10 km) on the Jiu River.

Since the simplest method of heat rejection is to discharge the wastewater of a power station cooling system to a river or lake directly, the delineation of thermal discharge should consider the thermal plume that appears at the wastewater outlet in the receiving water [15-18]. There are many interrelated factors which influence the rate at which thermal plumes disperse and heat is dissipated. The prediction of the size of a thermal plume and its temperature decay are generally made using hydro-physical modeling. The results of such modeling are important to the prediction of the ecological effects, apart from their importance to the operation of a power station. The results of simulations can be useful too, and compared with the results of the experimental measurements of water temperature [15-18,32,33].

Various approaches $[22,33,34]$ are used to estimate the capacity of water for heat dispersal. This includes mathematical or physical models that have also been developed to predict plume size and dilution behavior.

Whichever methods of plume modeling or measurement are used, knowledge of the detailed temperature patterns and behavior of the thermal plume, particularly of its degree of stability in time and space, are important to ecological impact predictions.

Starting from the above statement, the novelty of this study is that we conceive the method of the wastewater thermal pollutant vector that allows evaluation of the temperature in the water flow path created at certain distances in the river from the wastewater outlet channel.

Basically, the plane projection of the wastewater thermal pollutant vector is related to the water temperature (as a physical parameter). The discharged water can be a surface determined by a complex geometrical figure that can be reduced to an ellipse (point A in the wastewater outlet, and the ellipse center moved in the water flowing sense) [23,30-34]. Our statement is based on the non-uniform river flowing regimes, with a distribution of the flow front stronger in the central axis of the river lane and 
weaker to the shores (borders). This supports the assumption of the isothermal curves' modeling pattern of an ellipse type [30-32].

An analytical equation of an ellipse with center point $\mathrm{O}^{*}\left(x_{0}, y_{0}\right)$ and semi-axes $a$ and $b$ is:

$$
\frac{\left(x-x_{0}\right)^{2}}{a^{2}}+\frac{\left(y-y_{0}\right)^{2}}{b^{2}}-1=0
$$

The Plane Projection can be also developed for distances smaller than $250 \mathrm{~m}$. An example of a linear temperature distribution is provided if the Plane Projection can be developed for distances smaller than $250 \mathrm{~m}$ inside the main isothermal curve. The distribution of isothermal curves (see Table 1) if the plane projection is on a distance of $175 \mathrm{~m}$ in the main flowing lane of wastewater pollutant vector is depicted in Figure 5. In Figure 5, the horizontal and vertical axes of the reference system represent the longitudinal and transversal axes of the ellipse that models the wastewater discharged into the river. The reference system origin (namely, $0 \mathrm{~m}$ ) corresponds to the power station wastewater outlet. The colours in Table 1 correlate with the colours in Figure 5, which describe the distances on the isothermal curves.

Table 1. Distribution of isothermal curves.

\begin{tabular}{ccccc}
\hline No. & $\begin{array}{c}\text { Isothermal } \\
\text { Curve }\end{array}$ & $\begin{array}{c}\text { Iso }=\text { Isothermal } \\
\text { Indicator }\end{array}$ & $\begin{array}{c}\mathbf{D}_{\text {isom }}[\mathbf{m}]=\text { Distance on } \\
\text { Isothermal Curve }\end{array}$ & $\begin{array}{c}\mathbf{K}\left[{ }^{\circ} \mathbf{C} / \mathbf{m}\right]=\text { Longitudinal } \\
\text { Linearization Coefficient }\end{array}$ \\
\hline 1 & $\mathrm{IsO}_{33}$ & 33 & 35 & $1 / 35$ \\
2 & $\mathrm{IsO}_{32}$ & 32 & 35 & $1 / 35$ \\
3 & 31 & 35 & $1 / 35$ \\
4 & $\mathrm{IsO}_{31}$ & 30 & 35 & $1 / 35$ \\
5 & $\mathrm{IsO}_{30}$ & 29 & 35 & $1 / 35$ \\
\hline
\end{tabular}

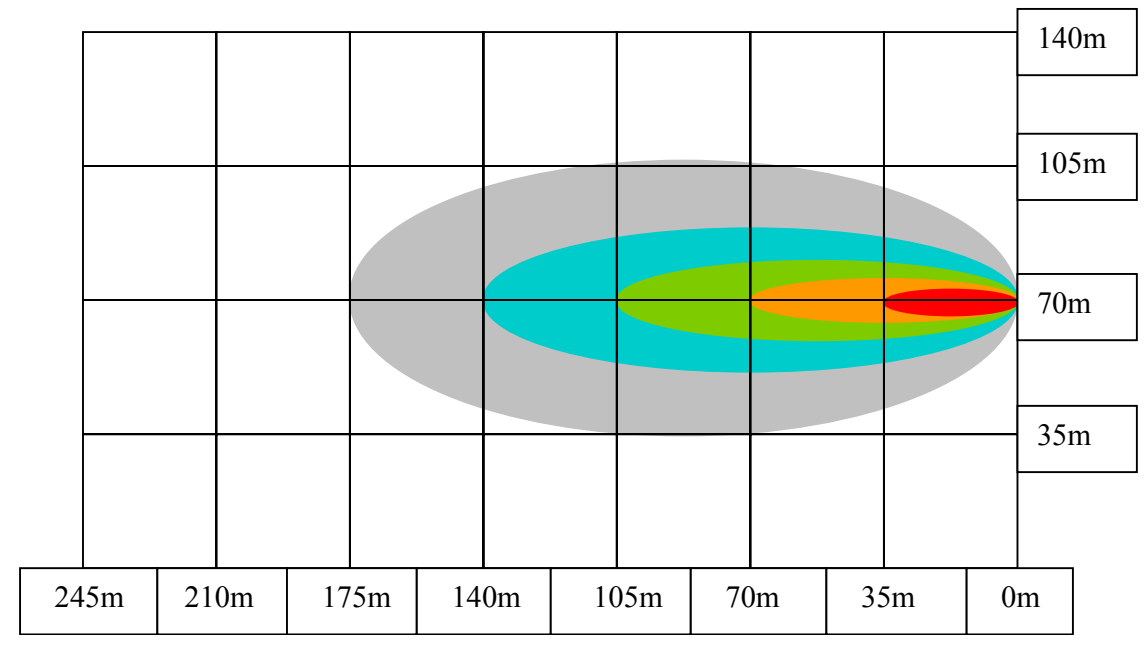

Figure 5. Isothermal curves: Iso33, Iso32, Iso31, Iso30, Iso29.

\subsection{The EDF Methodology for Evaluating the Wastewater Thermal Pollutant Vector}

From a design viewpoint, the discharged wastewater thermal pollutant vector has as flowing frame of a river laminar layer, variable from the point of the discharging vector outlet. Factors that interfere in the calculation of temperatures within the river, downstream from the outlet discharge point of a 
warm water flow, are numerous, variable and hard to calculate or measure. This is the reason for applying over time [8,16-19,23,24,28-34] an approximate calculus mainly linked to field measurements. The most simple formula does not take into consideration the temperature evolution downstream of the outlet of the wastewater discharging vector, having been concerned only with ensuring the mixture of warm water (from the coal-fired power plant) and the river water does not exceed a limit.

Assessment of temperature evolution in the river water downstream of the outlet, caused by a warm water discharge, is based on a theoretical method consisting of a formula with exponential factors.

Electricity of France (EDF) Group developed a mathematical model of temperature evolution in river water (since a warm water flow had been discharged on downstream by outlets):

$$
\Delta t=\Delta t_{\max } \cdot e^{-k x}
$$

where $\Delta t$ is the river water residual heating $x$ kilometers downstream from the warm water outlet; $\Delta t_{\max }$ is the river water maximum heating of the water mixture in the warm water outlet; $k$ is a climate correction factor, ranging between 0.001 and 0.01 ; and $x$ is the distance from the warm water outlet to the river section where the residual temperature is determined.

The mathematic model of temperature evolution in the river water, downstream of the warm water outlet, through the wastewater pollutant vector allows a reliable and accurate evaluation for river lengths of $10 \mathrm{~km}$ up to $50 \mathrm{~km}$. Numerical simulation is useful in the technical assessment of transient processes that vary gradually.

\subsection{EDF Methodology Applied to Thermoelectric Units of 330 MW of the Rovinari Power Station}

This case study takes into consideration operation of the thermoelectric power plant of Rovinari with an installed power corresponding to 3 energetic units $(n=3)$ of $330 \mathrm{MW}$, resulting in a total power generation of $990 \mathrm{MW}$ [23,30-32]. The investigation aims to assess the evolution of temperature, on the basis of the wastewater pollutant vector. This case study is performed under the following conditions:

- $\quad$ power plant capacity utilization of $75 \%$ of the installed power $(n=3)$;

- the outlet allows the discharge of wastewater provided by the three thermoelectric units of $330 \mathrm{MW}$;

- temperature assessment is based on the EDF methodology.

An AMD multiprocessor computer system with StatSoft STATISTICA-Version 7.0 software is used for data acquisition and processing. The simulation process of the EDF pattern for the wastewater thermal pollution vector involves four types of recordings on a $45 \mathrm{~km}$ river length, namely:

- $\quad$ temperature nomogram, for $k=0.001(n=3)$, as depicted in Figure 6;

- $\quad$ temperature nomogram, for $k=0.003(n=3)$, as depicted in Figure 7;

- $\quad$ temperature nomogram, for $k=0.004(n=3)$, as depicted in Figure 8. 
Function Plot (Temperatura: Vector Apa de Evacuare)

Function $=31.5^{\star} \operatorname{Exp}\left(-001^{\star} \mathrm{x}\right)$

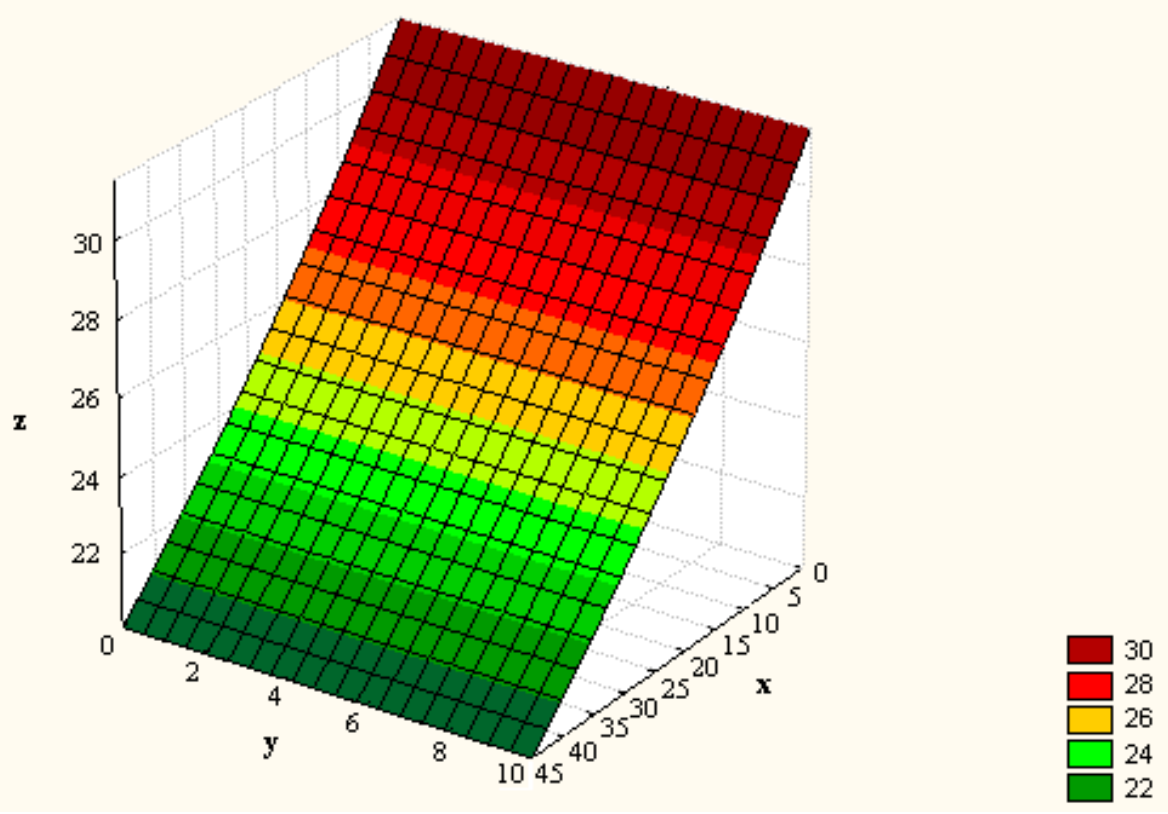

Figure 6. Water temperature nomogram for $k=0.001(n=3)$.

Function Flot (Temperatura: Vector Apa de E/acuare)

Function $=31.5^{\star} \operatorname{E} \times p\left(-0.03^{\star} x\right)$

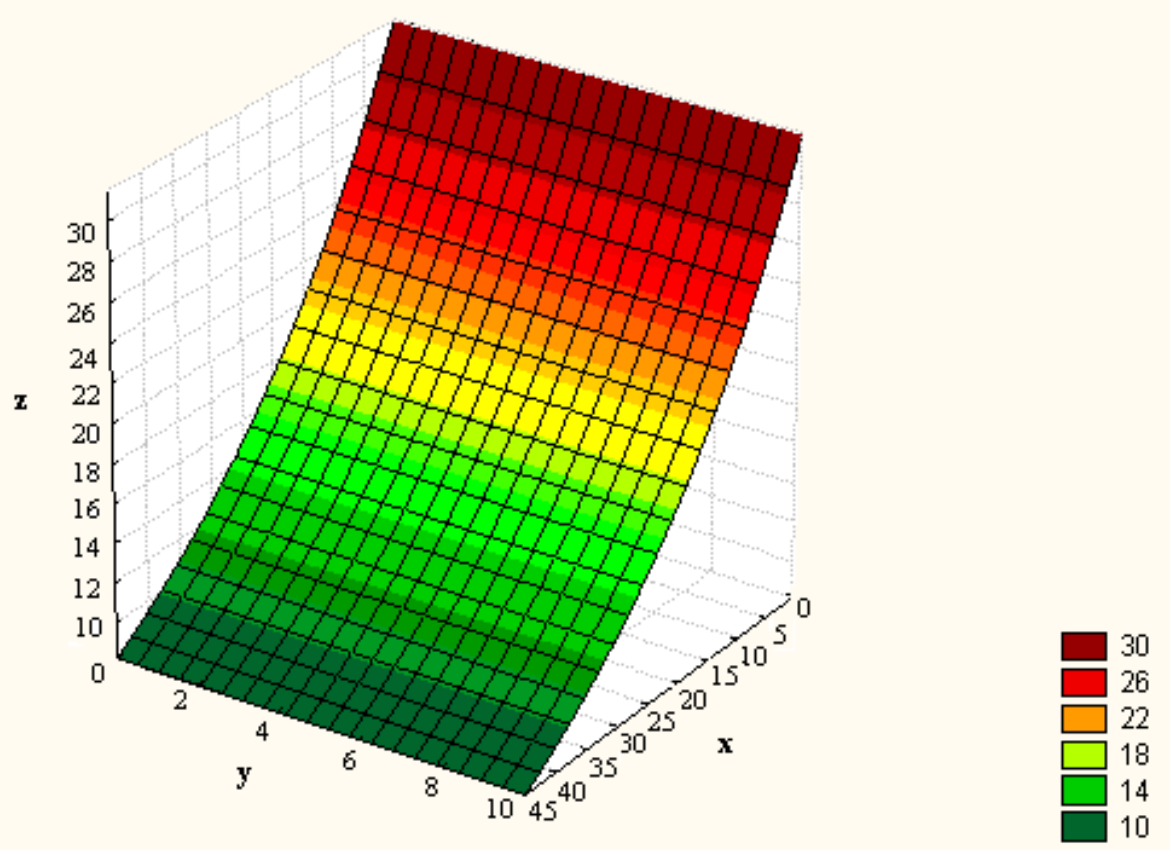

Figure 7. Water temperature nomogram for $k=0.003(n=3)$. 


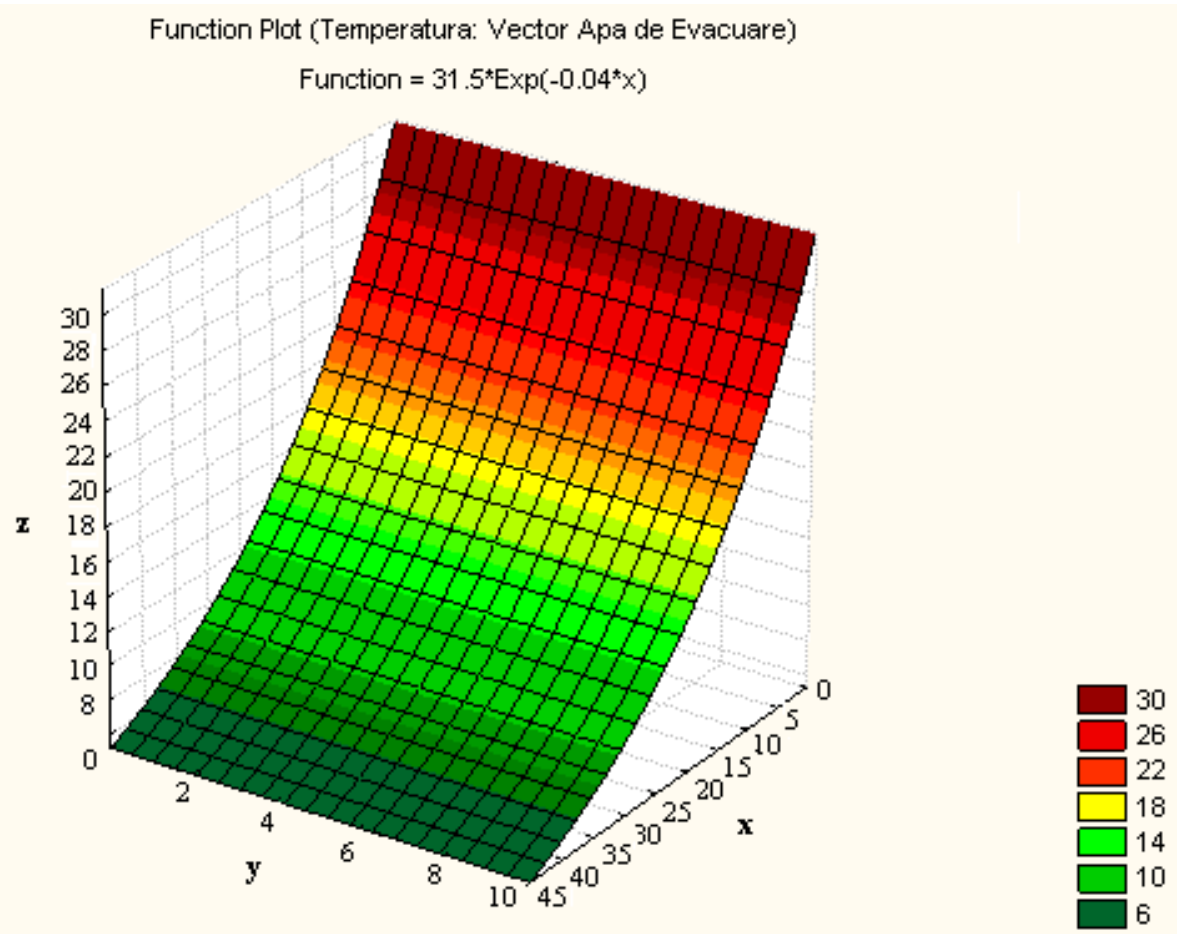

Figure 8. Water temperature nomogram for $k=0.004(n=3)$.

Note in Figures $6-8$ that the simulations have two variables:

- variable $x$, which represents the distance from the river outlet point of warm wastewater to the river section where the residual heating is calculated;

- variable $y$, denoted by $k$ and representing the climate correction factor, with values ranging between 0.001 and 0.01 .

The mathematical pattern response to the simulation is represented by the multivariable function $\mathrm{z}$ denoted by $\Delta t$ (river water residual heating at $\mathrm{x}$ kilometers from the warm water discharging outlet). The red colour indicates high values of temperature, obtained in the wastewater outlet.

It is emphasized in the mathematical model that the parameter $\Delta t_{\mathrm{m}}$ represents the maximum heating of river water after mixing with the warm water outlet.

\subsection{Experimental Validation of EDF Methodology Results on Thermoelectric Units of $330 \mathrm{MW}$ of Rovinari Power Stations}

Under the above mentioned conditions, for an acceptable evaluation of the mathematical pattern described by the EDF formula, it is necessary to join the simulations with experimental tests. For the experimental validation of the EDF model, on Jiu River have been performed recordings both for natural thermal load (JIU STN) on the upstream river and for the Rovinari thermal load (JIU STR) on river downstream. These data were obtained with the support of the Rovinari Power Plant staff. Table 2 and Figure 9 show the temperature evolution along the river length. In Table 2, we indicate with red bold font the river water temperature at the wastewater outlet of the Rovinari power plant. 
Table 2. Temperature $t$ and distance $x$ data series for Jiu River STN and Jiu River STR.

\begin{tabular}{|c|c|c|c|}
\hline $\begin{array}{c}t[C] \\
\text { Jiu River STN }\end{array}$ & $\begin{array}{c}t[C] \\
\text { Jiu River STR }\end{array}$ & $\begin{array}{c}x \\
{[\mathrm{~km}]}\end{array}$ & $\begin{array}{l}\text { Reading } \\
\text { Number }\end{array}$ \\
\hline 23.2 & 31.5 & 0.0 & 1 \\
\hline 23.1 & 31.2 & 0.5 & 2 \\
\hline 23.1 & 30.8 & 1.0 & 3 \\
\hline 23.1 & 30.5 & 1.5 & 4 \\
\hline 22.8 & 30.0 & 2.0 & 5 \\
\hline 22.9 & 29.5 & 2.5 & 6 \\
\hline 23.0 & 29.0 & 3.0 & 7 \\
\hline 23.0 & 28.0 & 3.5 & 8 \\
\hline 22.0 & 27.0 & 4.0 & 9 \\
\hline 22.5 & 26.0 & 4.5 & 10 \\
\hline 23.0 & 25.9 & 5.0 & 11 \\
\hline 22.5 & 25.5 & 5.5 & 12 \\
\hline 22.0 & 25.1 & 6.0 & 13 \\
\hline 22.2 & 25.1 & 6.5 & 14 \\
\hline 22.4 & 25.0 & 7.0 & 15 \\
\hline 22.6 & 24.9 & 7.5 & 16 \\
\hline 22.6 & 24.8 & 8.0 & 17 \\
\hline 22.7 & 24.8 & 8.5 & 18 \\
\hline 22.8 & 24.7 & 9.0 & 19 \\
\hline 23.0 & 24.7 & 9.5 & 20 \\
\hline 23.2 & 24.8 & 10.0 & 21 \\
\hline 23.6 & 24.9 & 10.5 & 22 \\
\hline 22.8 & 25.0 & 11.0 & 23 \\
\hline 23.0 & 25.1 & 11.5 & 24 \\
\hline 23.3 & 25.2 & 12.0 & 25 \\
\hline 23.6 & 25.2 & 12.5 & 26 \\
\hline 23.8 & 25.3 & 13.0 & 27 \\
\hline 24.2 & 25.3 & 13.5 & 28 \\
\hline 24.8 & 25.4 & 14.0 & 29 \\
\hline 25.0 & 25.5 & 14.5 & 30 \\
\hline
\end{tabular}

Normally, the medium river flow rate at the Rovinari site is roughly $47 \mathrm{~m}^{3} / \mathrm{s}$ [23-25]. The operation of three thermoelectric units in open circuit of the Rovinari power plant relies on this river flow, under the stability conditions for the relevant environmental parameters.

The measurement conditions assume the following:

(1) Maintaining in operation three thermoelectric units of $330 \mathrm{MW}$ in Rovinari for $5 \mathrm{~h}$ (4 h before measurement and $1 \mathrm{~h}$ during measuring).

(2) Positioning a human observer with a measuring instrument (precision digital thermometer) along the riverbed and in the mainstream of the river, at intervals of $5 \mathrm{~km}$.

(3) Establishing the trigger timing of the readings, chosen to be $10 \mathrm{AM}$, since according to legislation [21], this is the most appropriate time from the viewpoint of heat exchange between Jiu River and the environmental surroundings. 
(4) Performing the 11 temperature readings, over a period of $50 \mathrm{~min}$, at intervals of $5 \mathrm{~min}$.

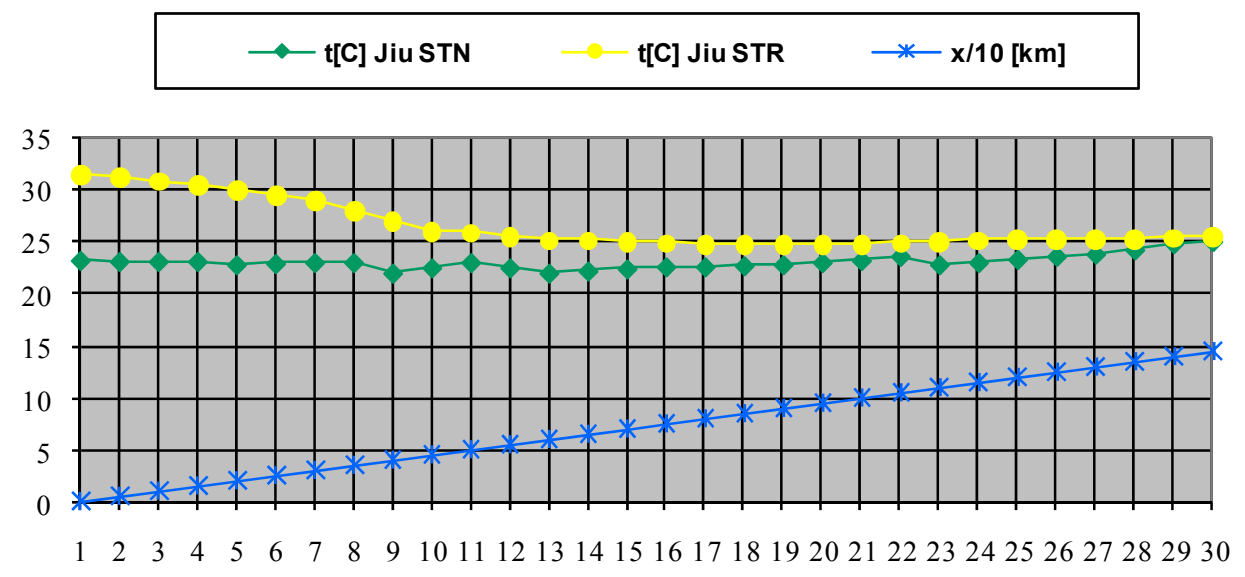

Figure 9. Diagram of $t$ and $x$ data series for Jiu River STN and Jiu River STR.

An AMD multiprocessor computer system with Microsoft Office-Version 7.0 software is used for data acquisition and processing.

The experimental validation of the EDF pattern for the wastewater thermal pollutant vector in this case study is shown in Figure 9, which shows data for temperature $t\left[{ }^{\circ} \mathrm{C}\right]$ and distance $x[\mathrm{~km}]$ on River Jiu, for the natural thermal load (Jiu River STN) and for the Rovinari thermal load (Jiu River STR).

In Table 3 and Figure 10, the isothermal curves Iso31, Iso30, Iso29, Iso28, Iso27 are depicted.

Table 3. Data of isothermal curves Iso31, Iso30, Iso29, Iso28, Iso27.

\begin{tabular}{ccccc}
\hline No. & $\begin{array}{c}\text { Isothermal } \\
\text { Curve }\end{array}$ & $\begin{array}{c}\text { Iso }=\text { Isothermal } \\
\text { Indicator }\end{array}$ & $\begin{array}{c}\Delta \boldsymbol{t}_{\mathbf{m}}\left[{ }^{\circ} \mathbf{C}\right]=\text { Outlet } \\
\text { Water Temperature }\end{array}$ & $\begin{array}{c}\boldsymbol{k}\left[\mathbf{k m}^{-1}\right]= \\
\text { Correction Factor }\end{array}$ \\
\hline 1 & $\mathrm{IsO}_{31}$ & 31 & 31.5 & 0.004 \\
2 & $\mathrm{IsO}_{30}$ & 30 & 31.5 & 0.004 \\
3 & 29 & 31.5 & 0.004 \\
4 & $\mathrm{IsO}_{29}$ & 28 & 31.5 & 0.004 \\
5 & $\mathrm{IsO}_{28}$ & 27 & 31.5 & 0.004 \\
\hline
\end{tabular}

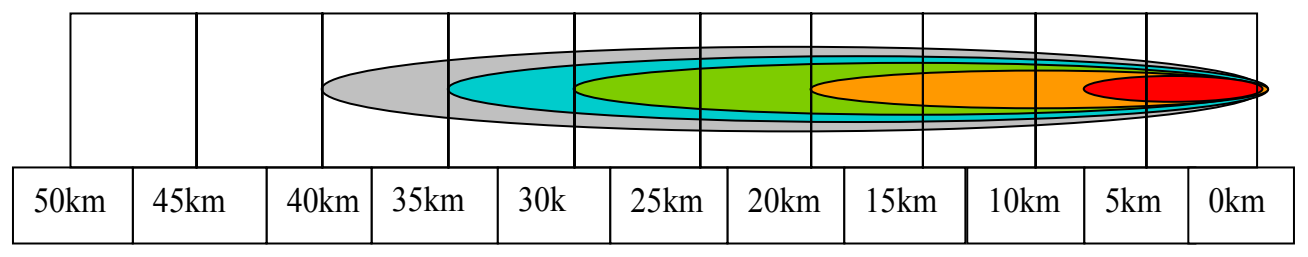

Figure 10. Isothermal curves: Iso31, Iso30, Iso29, Iso28, Iso27.

The colours in Table 3 correlate with the colours in Figure 10, which describe the distances on the isothermal curves.

Accordingly, it can be observed that:

- the limit $x=7.5 \mathrm{~km}$ for the isothermal curve Iso31 $=31{ }^{\circ} \mathrm{C}$;

- the limit $x=20 \mathrm{~km}$ for the isothermal curve Iso30 $=30^{\circ} \mathrm{C}$;

- the limit $x=30 \mathrm{~km}$ for the isothermal curve Iso29 $=29^{\circ} \mathrm{C}$; 
- the limit $x=35 \mathrm{~km}$ for the isothermal curve Iso28 $=28^{\circ} \mathrm{C}$;

- the limit $x=40 \mathrm{~km}$ for the isothermal curve Iso27 $=27^{\circ} \mathrm{C}$.

Consequently:

- for $k=0.003 \mathrm{~km}^{-1}, \Delta t_{\max }=31.5^{\circ} \mathrm{C}, n=3, \mathrm{P}_{\text {inst }} / \mathrm{unit}=330 \mathrm{MW}, \mathrm{P}_{\text {inst }}=990 \mathrm{MW}$, the maximum relative error is $\varepsilon_{\text {rel }} \leq 5.85 \%$;

- for $k=0.004 \mathrm{~km}^{-1}, \Delta t_{\max }=31.5^{\circ} \mathrm{C}, n=3$, Pinst/unit $=330 \mathrm{MW}, \mathrm{P}_{\text {inst }}=990 \mathrm{MW}$, the maximum relative error is $\varepsilon$ rel $\leq 3.66 \%$;

- for $k=0.005 \mathrm{~km}^{-1}, \Delta t_{\max }=31.5^{\circ} \mathrm{C}, n=3$, P inst $/$ unit $=330 \mathrm{MW}, \mathrm{P}_{\text {inst }}=990 \mathrm{MW}$, the maximum relative error is $\varepsilon$ rel $\leq 6.51 \%$;

- the optimum of the mathematical model according to relative error, under the conditions $\Delta t_{\max }=31.5^{\circ} \mathrm{C}, n=3, \mathrm{P}_{\text {inst }} / \mathrm{unit}=330 \mathrm{MW}$ and $\mathrm{P}_{\text {inst }}=990 \mathrm{MW}$, is given by $k=0.004 \mathrm{~km}^{-1}$.

\subsection{EDF Methodology Applied to Thermoelectric Units of $330 \mathrm{MW}$ of Rovinari and Turceni Power} Stations in Simultaneous Operation

Now, this case study takes into consideration the continuous operation of the thermoelectric power plant of Rovinari with a power corresponding to three energetic units $(n=3)$ of $330 \mathrm{MW}$ (resulting in a total power of $990 \mathrm{MW}$, which represents $75 \%$ of the total installed power) plus the continuous operation of the coal-fired power plant of Turceni with a power corresponding to three energetic units $(n=3)$ of $330 \mathrm{MW}$ (resulting the total power of $990 \mathrm{MW}$, which represents $50 \%$ of the total installed power) [26-28].

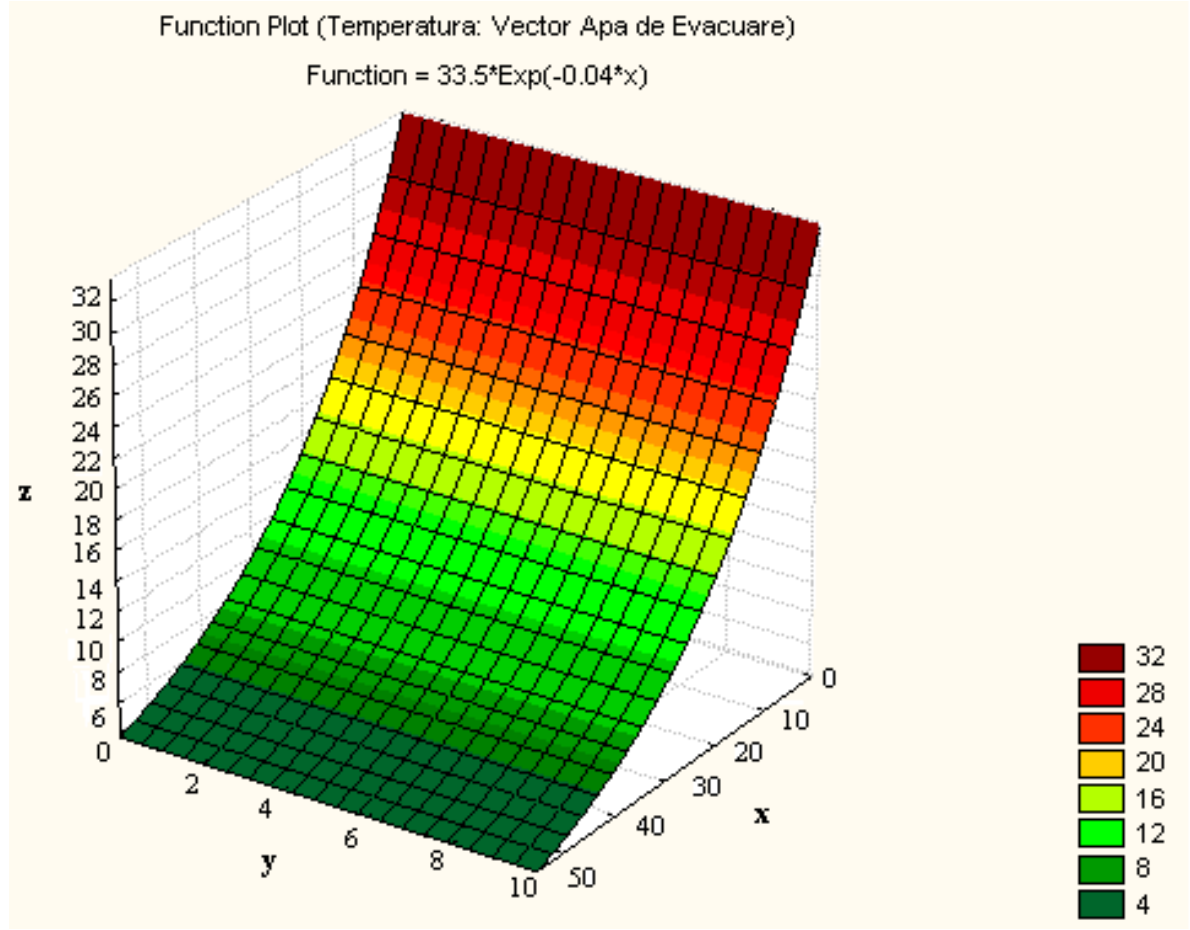

Figure 11. Water temperature nomogram for $k=0.004(n=6)$.

The wastewater thermal pollutant vector investigation aims to assess the correct evolution of temperature, on the basis of the EDF Methodology. 
Note in this case that the outlets allow the discharge of wastewater provided by three thermoelectric units of $330 \mathrm{MW}$ from the Rovinari power plant and three thermoelectric units of $330 \mathrm{MW}$ from the Turceni power plant.

Following the same procedure as before, the simulation process of the EDF pattern for the wastewater pollution vector involves four types of recording on a $45 \mathrm{~km}$ river length, namely:

- temperature nomogram, $k=0.004(n=6)$, depicted by Figure 11, as an example;

- $\quad$ temperature nomogram, $k=0.0054(n=6)$;

- $\quad$ temperature nomogram, $k=0.006(n=6)$.

\subsection{Experimental Validation of EDF Methodology Results on Thermoelectric Units of $330 \mathrm{MW}$ of} Rovinari and Turceni Power Stations in Simultaneous Operation

To provide experimental validation of the EDF model, in Jiu River, readings are taken [30-32] both for natural thermal load (JIU STN) in the upstream river and for the Rovinari and Turceni thermal loads (JIU STRT) in the downstream river for Turceni.

Normally, the medium river flow rate at the Rovinari site is roughly $47 \mathrm{~m}^{3} / \mathrm{s}$, and at the Turceni site is roughly $54.5 \mathrm{~m}^{3} / \mathrm{s}$. Operation of three thermoelectric units, in open circuit of the Rovinari and Turceni power plants relies on these river flow rates, under the stability conditions for the relevant environmental parameters.

Under the same measurement conditions as before, the experimental validation of the EDF pattern for the wastewater thermal pollutant vector in this case study is shown in Table 4 and Figure 12, which depict the temperature $t\left[{ }^{\circ} \mathrm{C}\right]$ and distance $x[\mathrm{~km}]$ on River Jiu for natural thermal load (Jiu River STN) and for the Rovinari and Turceni thermal loads (Jiu River STRT). In Table 4, we indicate with red bold font the river water temperature points at the wastewater outlets of the Rovinari and Turceni power plants. In Figure 13, the isothermal curves Iso33, Iso30, Iso29, Iso28, Iso27 are depicted.

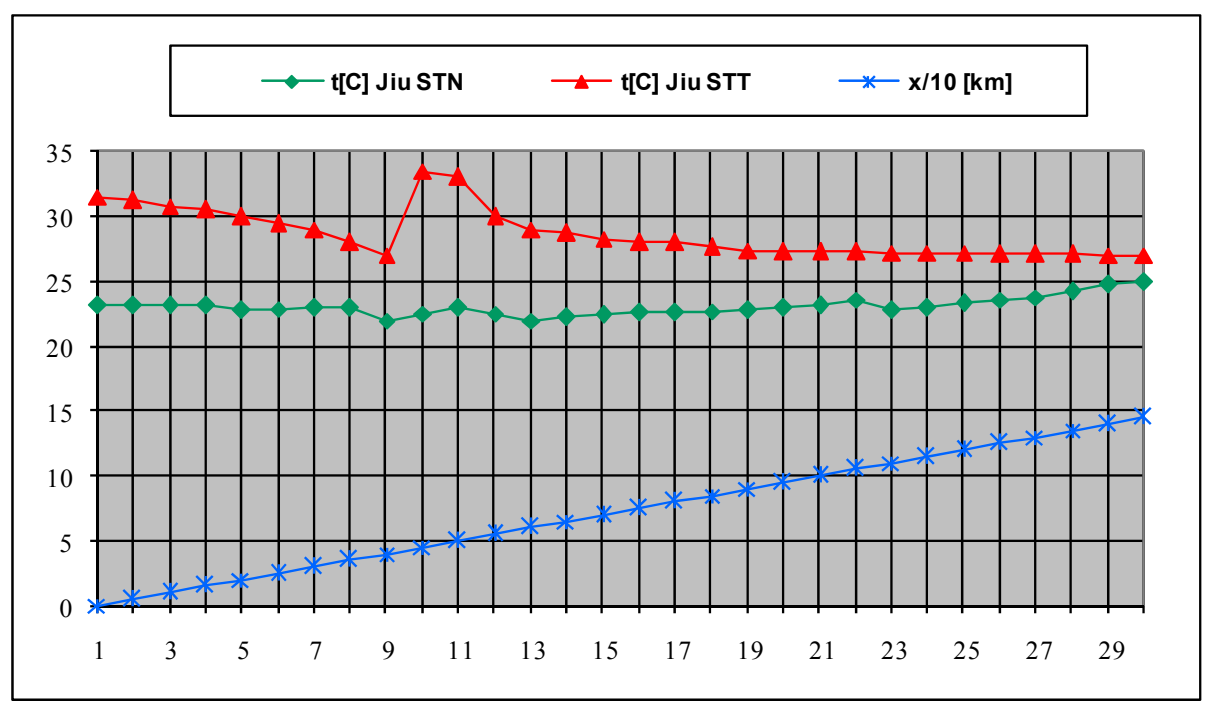

Figure 12. Diagram of $t$ and $x$ data series for Jiu River STN and Jiu River STRT. 


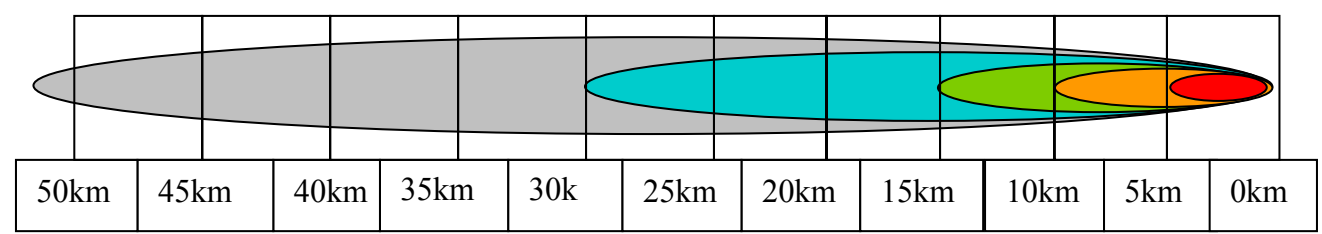

Figure 13. Isothermal curves: Iso33, Iso30, Iso29, Iso28, Iso27.

Table 4. Temperature $t$ and distance $x$ data series for Jiu River STN and Jiu River STRT.

\begin{tabular}{|c|c|c|c|}
\hline $\begin{array}{c}t[\mathrm{C}] \\
\text { Jiu STN }\end{array}$ & $\begin{array}{c}t[C] \\
\text { Jiu STRT }\end{array}$ & $\begin{array}{l}x / 10 \\
{[\mathrm{~km}]} \\
\end{array}$ & $\begin{array}{l}\text { Reading } \\
\text { Number }\end{array}$ \\
\hline 23.2 & 31.5 & 0.0 & 1 \\
\hline 23.1 & 31.2 & 0.5 & 2 \\
\hline 23.1 & 30.8 & 1.0 & 3 \\
\hline 23.1 & 30.5 & 1.5 & 4 \\
\hline 22.8 & 30.0 & 2.0 & 5 \\
\hline 22.9 & 29.5 & 2.5 & 6 \\
\hline 23.0 & 29.0 & 3.0 & 7 \\
\hline 23.0 & 28.0 & 3.5 & 8 \\
\hline 22.0 & 27.0 & 4.0 & 9 \\
\hline 22.5 & 33.5 & 4.5 & 10 \\
\hline 23.0 & 33.0 & 5.0 & 11 \\
\hline 22.5 & 30.0 & 5.5 & 12 \\
\hline 22.0 & 29.0 & 6.0 & 13 \\
\hline 22.2 & 28.7 & 6.5 & 14 \\
\hline 22.4 & 28.3 & 7.0 & 15 \\
\hline 22.6 & 28.0 & 7.5 & 16 \\
\hline 22.6 & 28.0 & 8.0 & 17 \\
\hline 22.7 & 27.7 & 8.5 & 18 \\
\hline 22.8 & 27.4 & 9,0 & 19 \\
\hline 23.0 & 27.3 & 9.5 & 20 \\
\hline 23.2 & 27.3 & 10.0 & 21 \\
\hline 23.6 & 27.3 & 10.5 & 22 \\
\hline 22.8 & 27.2 & 11.0 & 23 \\
\hline 23.0 & 27.2 & 11.5 & 24 \\
\hline 23.3 & 27.2 & 12.0 & 25 \\
\hline 23.6 & 27.1 & 12.5 & 26 \\
\hline 23.8 & 27.1 & 13.0 & 27 \\
\hline 24.2 & 27.1 & 13.5 & 28 \\
\hline 24.8 & 27.0 & 14.0 & 29 \\
\hline 25.0 & 27.0 & 14.5 & 30 \\
\hline
\end{tabular}

According to the data depicted above, it can be observed that:

- the limit $x=5 \mathrm{~km}$ for the isothermal curve $\mathrm{Iso}_{33}=33^{\circ} \mathrm{C}$;

- the limit $x=10 \mathrm{~km}$ for the isothermal curve Iso $30=30^{\circ} \mathrm{C}$;

- the limit $x=15 \mathrm{~km}$ for the isothermal curve Iso29 $=29^{\circ} \mathrm{C}$;

- the limit $x=30 \mathrm{~km}$ for the isothermal curve Iso28 $=28{ }^{\circ} \mathrm{C}$; 
- $\quad$ the limit $x=52.5 \mathrm{~km}$ for the isothermal curve Iso27 $=27^{\circ} \mathrm{C}$.

Consequently:

- for $k=0.004 \mathrm{~km}^{-1}, \Delta t_{\max }=31.5{ }^{\circ} \mathrm{C}, n=6$, P Pinst $_{\text {unit }}=330 \mathrm{MW}$, P inst $=1980 \mathrm{MW}$, the maximum relative error is $\varepsilon_{\text {rel }} \leq 8.79 \%$;

- for $k=0.0054 \mathrm{~km}^{-1}, \Delta t_{\max }=31.5{ }^{\circ} \mathrm{C}, n=6$, $\mathrm{P}_{\text {inst }} / \mathrm{unit}=330 \mathrm{MW}, \mathrm{P}_{\text {inst }}=1980 \mathrm{MW}$, the maximum relative error is $\varepsilon$ rel $\leq 6.53 \%$;

- for $k=0.006 \mathrm{~km}^{-1}, \Delta t_{\max }=31.5{ }^{\circ} \mathrm{C}, n=6$, Pinst $/$ unit $=330 \mathrm{MW}$, Pinst $=1980 \mathrm{MW}$, the maximum relative error is $\varepsilon_{\text {rel }} \leq 9.09 \%$.

- the optimum of the mathematical model according to relative error, under the conditions $\Delta t_{\max }=31.5^{\circ} \mathrm{C}, n=6, \mathrm{P}_{\text {inst }} / \mathrm{unit}=330 \mathrm{MW}, \mathrm{P}_{\text {inst }}=1980 \mathrm{MW}$, is given by $k=0.0054 \mathrm{~km}^{-1}$.

\subsection{EDF Methodology Applied to Thermoelectric Units of 330 MW of Rovinari, Turceni and Craiova} Power Stations in Simultaneous Operation

The third situation in this case study considers the continuous, simultaneous operation of three coal-fired power plants which are connected in a cascade manner, from the cooling system viewpoint, since they are supplying freshwater from and discharged wastewater in the Jiu River. This case study is performed under the following conditions:

- the Rovinari power plant operates with three units of $330 \mathrm{MW}$ (capacity utilization of $75 \%$ of the installed power);

- the Turceni power plant operates with three units of $330 \mathrm{MW}$ (capacity utilization of 50\% of the installed power);

- the Craiova power plant operates with three units of $330 \mathrm{MW}$ (capacity utilization of $100 \%$ of the installed power);

- the total installed power is $2970 \mathrm{MW}$;

- the outlets of these power plants allow the discharge of wastewater provided by the nine thermoelectric blocks of $330 \mathrm{MW}$, comprised of three units from each power plant;

- temperature assessment is based on the EDF methodology.

Following the same procedure, the simulation process of the EDF pattern for the wastewater pollution vector involves four types of recordings on a $45 \mathrm{~km}$ river length, namely:

- temperature nomogram, $k=0.001(n=9)$, depicted by Figure 14, as an example;

- $\quad$ temperature nomogram, $k=0.002(n=9)$;

- $\quad$ temperature nomogram, $k=0.003(n=9)$. 


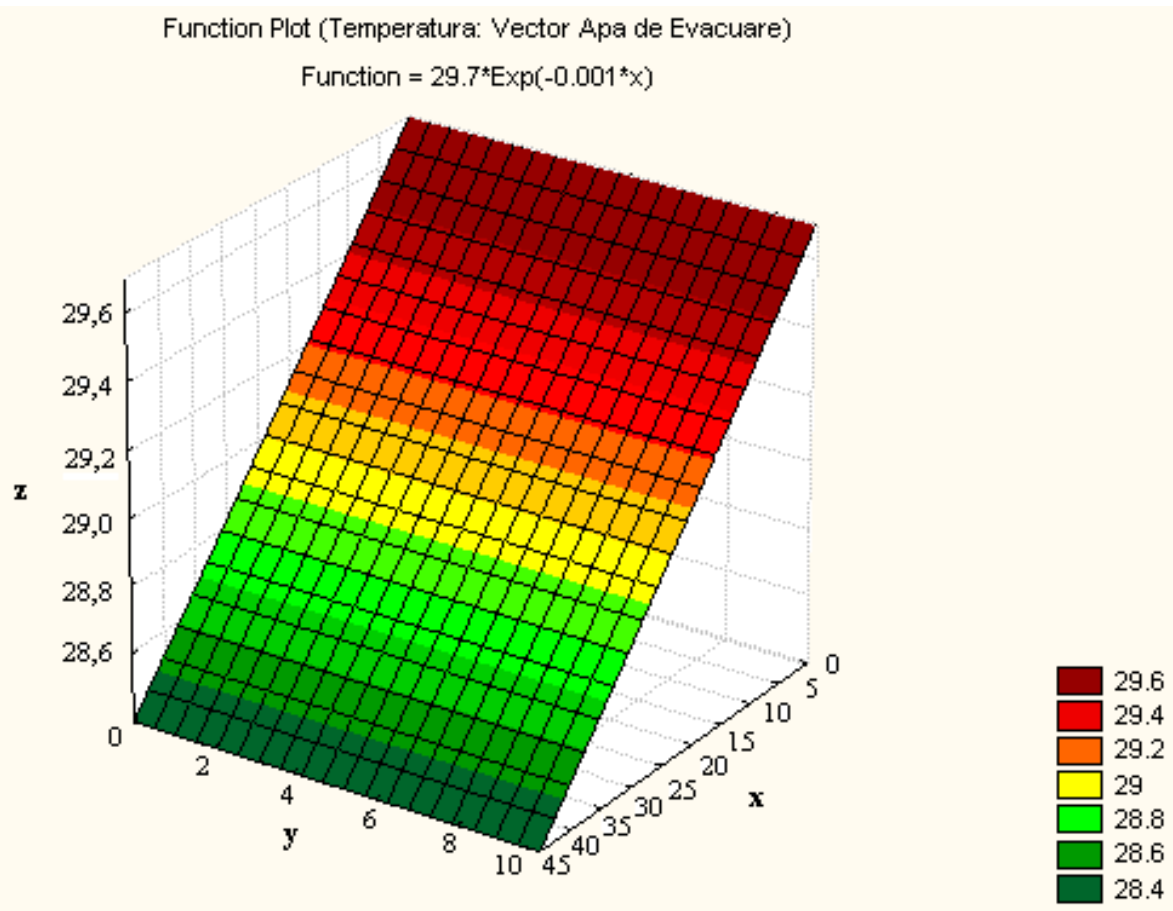

Figure 14. Water temperature nomogram for $k=0.001(n=9)$.

\subsection{Experimental Validation of EDF Methodology Results of Thermoelectric Units of $330 \mathrm{MW}$ of} Rovinari, Turceni and Craiova Power Stations in Simultaneous Operation

To provide experimental validation of the EDF model, on Jiu River readings are taken both for the natural thermal load (JIU STN) on the river upstream, and for the Rovinari and Turceni and Craiova thermal loads (JIU STRTC) on the downstream river in Craiova [29-32].

Normally, the medium river flow at the Rovinari site is roughly $47 \mathrm{~m}^{3} / \mathrm{s}$, while at the Turceni site it is roughly $54.5 \mathrm{~m}^{3} / \mathrm{s}$ and at the Craiova site it is roughly $80 \mathrm{~m}^{3} / \mathrm{s}$.

The experimental validation of the EDF pattern for the wastewater pollutant vector in this case study is illustrated in Table 5 and Figure 15. That diagram depicts the temperature $t\left[{ }^{\circ} \mathrm{C}\right]$ and distance $x[\mathrm{~km}]$ on River Jiu, for the natural thermal load (Jiu River STN) and for the Rovinari + Turceni + Craiova thermal loads (Jiu River STRTC). In Table 5, we indicate with red bold fonts the river water temperature points at the wastewater outlets of the Rovinari, Turceni and Craiova power plants. In Figure 16, the isothermal curves Iso29.5, Iso29, Iso28.5, Iso28 are shown.

Table 5. Temperature $t$ and distance $x$ data series for Jiu River STN and Jiu River STRTC.

\begin{tabular}{cccc}
\hline $\boldsymbol{t}[\mathbf{C}]$ & $\begin{array}{c}\boldsymbol{t}[\mathbf{C}] \\
\text { Jiu STRTC }\end{array}$ & $\begin{array}{c}\boldsymbol{x} / \mathbf{1 0} \\
{[\mathbf{k m}]}\end{array}$ & $\begin{array}{c}\text { Reading } \\
\text { Number }\end{array}$ \\
\hline 23.2 & $\mathbf{3 1 . 5}$ & 0.0 & 1 \\
23.1 & 31.2 & 0.5 & 2 \\
23.1 & 30.8 & 1.0 & 3 \\
23.1 & 30.5 & 1.5 & 4 \\
22.8 & 30.0 & 2.0 & 5 \\
\hline
\end{tabular}


Table 5. Cont.

\begin{tabular}{cccc}
\hline $\boldsymbol{t}[\mathbf{C}]$ & $\begin{array}{c}\boldsymbol{t}[\mathbf{C}] \\
\text { Jiu STRTC }\end{array}$ & $\begin{array}{c}\boldsymbol{x} / \mathbf{1 0} \\
{[\mathbf{k m}]}\end{array}$ & $\begin{array}{c}\text { Reading } \\
\text { Number }\end{array}$ \\
\hline 22.9 & 29.5 & 2.5 & 6 \\
23.0 & 29.0 & 3.0 & 7 \\
23.0 & 28.0 & 3.5 & 8 \\
22.0 & 27.0 & 4.0 & 9 \\
22.5 & 33.5 & 4.5 & 10 \\
23.0 & $\mathbf{3 3 . 0}$ & 5.0 & 11 \\
22.5 & 30.0 & 5.5 & 12 \\
22.0 & 29.0 & 6.0 & 13 \\
22.2 & 28.7 & 6.5 & 14 \\
22.4 & 28.3 & 7.0 & 15 \\
22.6 & 28.0 & 7,5 & 16 \\
22.6 & 28.0 & 8.0 & 17 \\
22.7 & 27.7 & 8.5 & 18 \\
22.8 & 27.4 & 9.0 & 19 \\
23.0 & 27.3 & 9.5 & 20 \\
23.2 & $\mathbf{2 9 . 7}$ & 10.0 & 21 \\
23.6 & 29.1 & 10.5 & 22 \\
22.8 & 28.9 & 11.0 & 23 \\
23.0 & 28.7 & 11,5 & 24 \\
23.3 & 28.5 & 12.0 & 25 \\
23,6 & 28.4 & 12.5 & 26 \\
23.8 & 28.3 & 13.0 & 27 \\
24.2 & 28.2 & 13.5 & 28 \\
24,8 & 28.1 & 14.0 & 30 \\
25.0 & 28.0 & 14.5 & \\
\hline & & & 29 \\
\hline
\end{tabular}

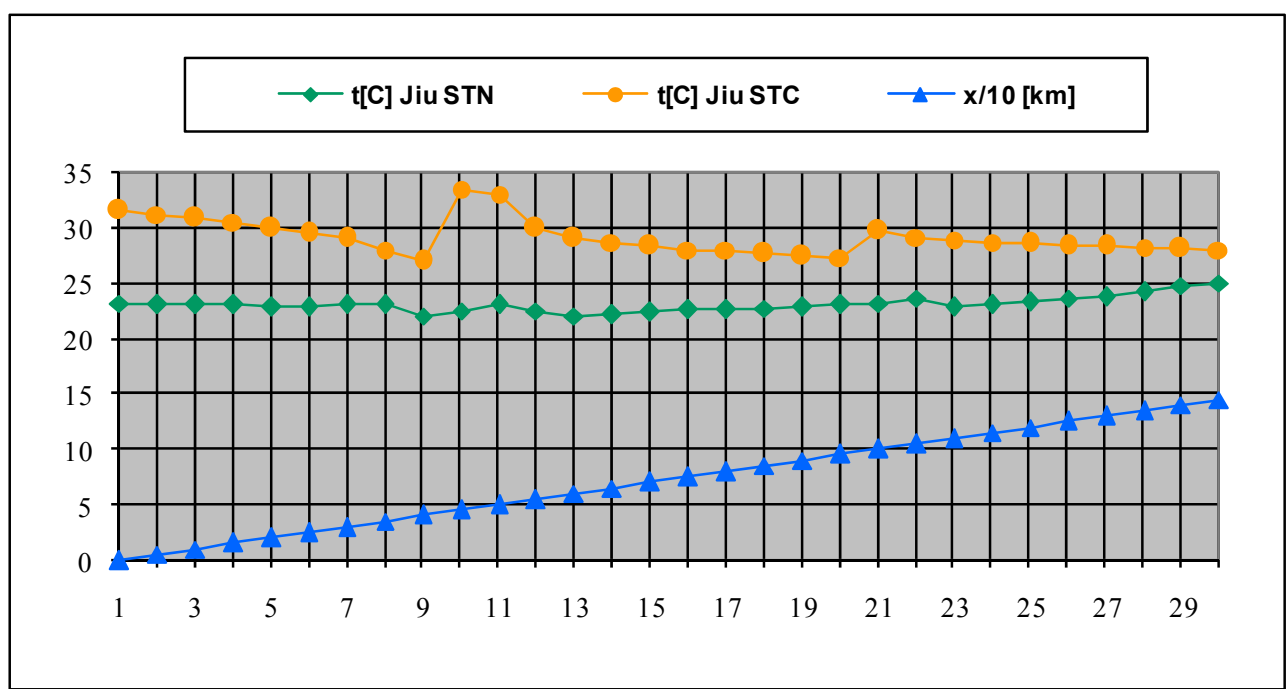

Figure 15. Diagram of $t$ and $x$ data series for Jiu River STN and Jiu River STRTC. 


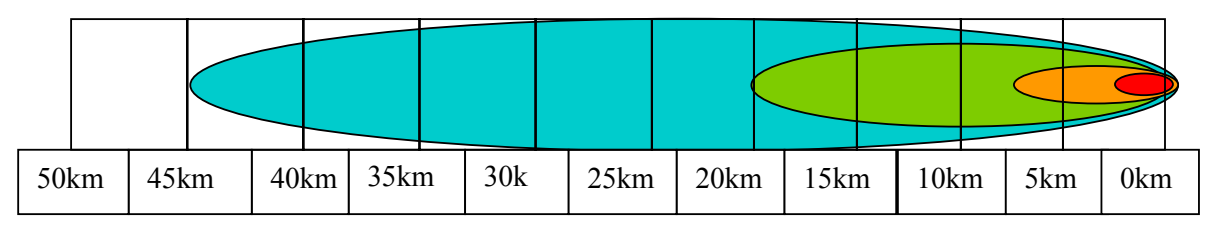

Figure 16. Isothermal curves: Iso29.5, Iso29, Iso28.5, Iso28.

Accordingly, it can be observed that:

- the limit $x=2.5 \mathrm{~km}$ for the isothermal curve Iso29.5 $=29.5^{\circ} \mathrm{C}$;

- the limit $x=7.5 \mathrm{~km}$ for the isothermal curve Iso $29_{2}=29^{\circ} \mathrm{C}$;

- the limit $x=20 \mathrm{~km}$ for the isothermal curve Iso28.5 $=28.5^{\circ} \mathrm{C}$;

- the limit $x=45 \mathrm{~km}$ for the isothermal curve Iso28 $=28^{\circ} \mathrm{C}$.

Consequently:

- for $k=0.001 \mathrm{~km}^{-1}, \Delta t_{\max }=29.7^{\circ} \mathrm{C}, n=9$, $\mathrm{P}_{\text {inst }} / \mathrm{unit}=330 \mathrm{MW}, \mathrm{P}_{\text {inst }}=2970 \mathrm{MW}$, the maximum relative error is $\varepsilon_{\text {rel }} \leq 2.15 \%$;

- for $k=0.002 \mathrm{~km}^{-1}, \Delta t_{\max }=29.7^{\circ} \mathrm{C}, n=9$, $\mathrm{P}_{\text {inst }} / \mathrm{unit}=330 \mathrm{MW}, \mathrm{P}_{\text {inst }}=2970 \mathrm{MW}$, the maximum relative error is $\varepsilon_{\text {rel }} \leq 3.06 \%$;

- for $k=0.003 \mathrm{~km}^{-1}, \Delta t_{\max }=29.7^{\circ} \mathrm{C}, n=9$, $\mathrm{P}_{\text {inst }} / \mathrm{unit}=330 \mathrm{MW}, \mathrm{P}_{\text {inst }}=2970 \mathrm{MW}$, the maximum relative error is $\varepsilon_{\text {rel }} \leq 7.32 \%$;

- the optimum of the mathematical model according to relative error, under the conditions $\Delta t_{\max }=31.5^{\circ} \mathrm{C}, n=9, \mathrm{P}_{\text {inst }} /$ unit $=330 \mathrm{MW}, \mathrm{P}_{\text {inst }}=2970 \mathrm{MW}$, is given by $k=0.001 \mathrm{~km}^{-1}$.

Note that the temperature decrease in the Jiu River water downstream of the wastewater outlets of the Rovinari, Turceni and Craiova power plants, respectively, is determined by the increase of Jiu River water flow due to its affluent rivers. These included the Jilt River (after the Rovinari power plant), the Gilort River and Motru River (after the Turceni power plant) and the Amaradia River (after the Craiova power plant), and can be seen in the map of the Jiu River in Figure 17.

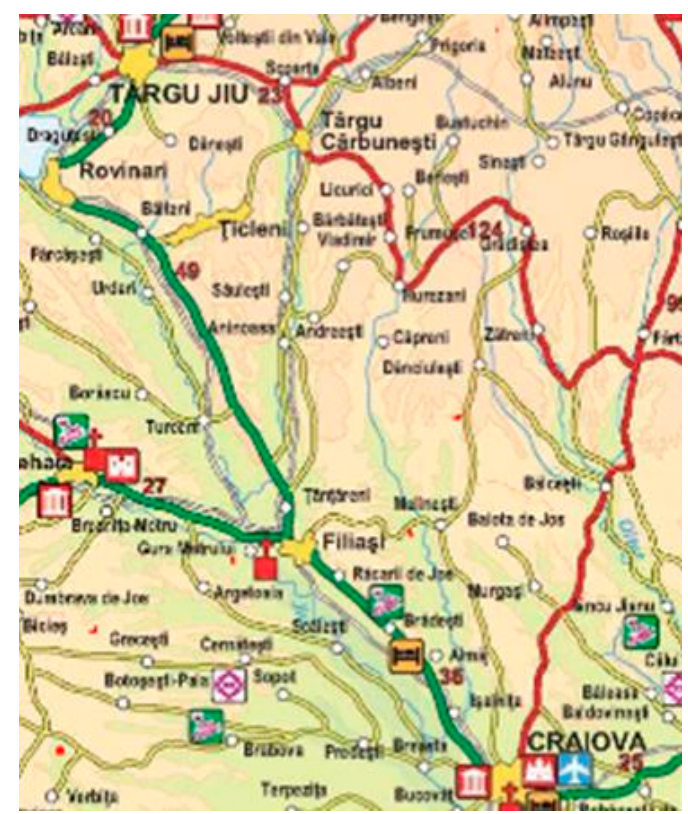

Figure 17. Map of Jiu River. 


\section{Conclusions}

The thermal pollution caused by three thermoelectric power plants located along a river has been successfully evaluated. Thermoelectric power plants are one of the main causes of thermal pollution. Such plants pump water directly from rivers, lakes or the ocean, to cool the turbine condensers. During the process, which usually involves once-through cooling, the water becomes warmer than the source water, so that the wastewater is returned to its source at temperatures significantly higher than the freshwater that originally entered the electric generation station. Discharging the warmer water to a river or lake can cause a significant environmental impact in terms of downstream thermal pollution, and wildlife can be affected.

In the present analysis, with three thermoelectric units of $330 \mathrm{MW}$ operating in each of the Rovinari and Turceni power plants, and assuming an average river flow rate of $47 \mathrm{~m}^{3} / \mathrm{s}$ at the Rovinari site and $54.5 \mathrm{~m}^{3} / \mathrm{s}$ at the Turceni site, the effect of wastewater discharging in the Jiu River is found to be marginally acceptable.

Simultaneous operation of the thermoelectric units, in open circuit, (meaning, supplying fresh water from the river and discharging wastewater in the river, without using the cooling towers of the power plant) of the Rovinari, Turceni and Craiova power stations relies on the Jiu River flow, under the stability conditions for relevant environmental parameters. In an undeveloped regime of the river system, the flow of the Jiu River does not ensure the functioning in open circuit at the installed power of this chain of three coal-fired power plants connected in a cascade manner (from the cooling system viewpoint) along the Jiu River. If the coal-fired power plants of Rovinari and Turceni operate in open circuit (meaning without recirculation of the water in the cooling system of the power plant) at full capacity (with four and six thermoelectric units, respectively), then the environmental impact caused by wastewater thermal pollution, concerning aquatic ecosystems, can be significant. In these conditions, the operation of tower cooling systems in these power stations may prove necessary.

The EDF mathematic model of temperature evolution within the water of the Jiu River downstream from the outlet of the warm water pollutant vector allows an acceptable evaluation in terms of errors, for river lengths of $10-50 \mathrm{~km}$.

For an acceptable evaluation, it is necessary to combine the simulation results (based on EDF mathematical pattern) with experimental tests for wastewater pollutant vector.

It would be useful to assess overall projections of the wastewater thermal pollutant vector, for both small and large distances.

Another environmental concern is related to abnormal weather conditions, such as arid summer or strong winter frost. Then, either the electrical capability of the coal-fired power plant (operating with a once-through cooling system) would decrease, or the aquatic ecosystems would be affected by the operation of the thermoelectric units. Then, from the viewpoint of environmental stewardship, a closed-cycle cooling system would be the Best Available Technology (BAT) for the thermoelectric power plants for reducing or avoiding adverse environmental impacts.

Within the framework of industrial ecology, as a sustainable policy of the thermoelectric power plants, it is also highlighted that the heat losses of the thermal wastewater of a power plant cooling system can be reduced by using the waste heat for heating local homes and/or greenhouses and/or industries. 


\section{Acknowledgments}

The authors gratefully acknowledge the support provided by their respective institutions in support of this research.

\section{Author Contributions}

Marc A. Rosen and Cornelia A. Bulucea designed the research and drafted the manuscript. Nikos E. Mastorakis and Constantin Brindusa carried out the wastewater thermal pollutant vector simulation. Carmen A. Bulucea and Andreea C. Jeles developed the EDF methodology for the thermoelectric power plants of Turceni, Rovinari and Craiova, and participated in the experimental tests. All authors have read, enhanced and approved the final manuscript.

\section{Conflicts of Interest}

The authors declare no conflict of interest.

\section{References}

1. El-Haggar, S. Sustainable Industrial Design and Waste Management: Cradle to Cradle for Sustainable Development; Elsevier Academic Press: Burlington, MA, USA, 2007.

2. Ehrenfeld, S. Industrial Ecology: A New Framework for Product and Process Design. J. Clean. Prod. 1997, 5, 87-95.

3. Dincer, I.; Rosen, M.A. Exergy: Energy, Environment and Sustainable Development, 2nd ed.; Elsevier: Oxford, UK, 2013.

4. Rosen, M.A.; Dincer, I. Exergy analysis of waste emissions. Int. J. Energy Res. 1999, 23, 1153-1163.

5. Drbal, L.F., Borton, P., Westra, K.L., Erikson, R.B., Eds. Power Plant Engineering; Black \& Veatch Publishing House: New York, NY, USA, 1996.

6. Penney, S.; Bell, J.; Balbus, J. Estimating the Health Impacts of Coal-Fired Power Plants Receiving International Financing. Report of Environmental Defence Fund, 2009. Available online: http://www.edf.org/documents/9553_coal-plants-health-impacts.pdf (accessed on 12 August 2014).

7. Lockwood, A.; Welker-Hood, K.; Rauch, M.; Gottlieb, B. Cault Assault on Human Health. Available online: http://www.psr.org/assets/pdfs/psr-coal-fullreport.pdf (accessed on 11 May 2015).

8. Istrate, M.; Gusa, M. Impactul Producerii, Transportului si Distributiei Energiei Electrice Asupra Mediulu (Environmental Impact of Electric Energy Generation and Transportation); AGIR Publishing House: Bucharest, Romania, 2000.

9. Laws, E.A. Aquatic Pollution: An Introductory Text; John Wiley and Sons: New York, NY, USA, 2000.

10. Goel, P.K. Water Pollution: Causes, Effects and Control; New Age International: New Delhi, India, 2006.

11. Edinger, J.E.; Geyer, J.C. Heat Exchange in the Environment; Edison Electric Institute: New York, NY, USA, 1965. 
12. Langford, T.E.L. Ecological Effects of Thermal Discharges; Elsevier Applied Science Publishers Ltd.: London, UK; New York, NY, USA, 1990.

13. Hogan, M.; Patmore, L.C.; Seidman, H. Statistical Prediction of Dynamic Thermal Equilibrium Temperatures Using Standard Meteorological Data Bases; Report EPA-660/2-73-003; U.S. Environmental Protection Agency (EPA), Office of Research and Development: Washington, DC, USA, 1973.

14. Termuehlen, H.; Emsperger, W. Clean and Efficient Coal-Fired Power Plants; ASME (American Society of Mechanical Engineers) Press: New York, NY, USA, 2003.

15. Vidic, R.D.; Dzombak, D.A.; Hsieh, M.-K.; Li, H.; Chien, S.-H.; Feng, Y.; Chowdhury, I.; Monnell, J.D. Reuse of Treated Internal or External Wastewaters in the Cooling Systems of CoalBased Thermoelectric Power Plants. Available online: http://citeseerx.ist.psu.edu/viewdoc/ download?doi=10.1.1.226.3456\&rep=rep1\&type=pdf (accessed on 10 March 2015).

16. American Public Health Association (APHA); American Water Works Association (AWWA); Water Environment Federation (WEF). Standard Methods for the Examination of Water \& Wastewater: Centennial Edition, 21st ed.; APHA-AWWA-WEF: Washington, DC, USA, 2005.

17. Hanafiah, M.M. Quantifying Effects of Physical, Chemical and Biological Stressors in Life Cycle Assessment. Ph.D. Thesis, Radboud University Nijmegen, Nijmegen, The Netherlands, 2013; Chapter 4 Characterization Factors for Thermal Pollution in Freshwater Aquatic Environments, pp. 69-126. Available online: http://repository.ubn.ru.nl/bitstream/handle/2066/111217/ 111217.pdf\#page=70 (accessed on 17 April 2015).

18. Electric Power Research Institute (EPRI). Water \& Sustainability (Volume 3): U.S. Water Consumption for Power Production-The Next Half Century; Technical Report EPRI, 2002; Available online: http://www.circleofblue.org/waternews/wp-content/uploads/2010/08/EPRIVolume-3.pdf (accessed on 17 April 2015).

19. NETL. Estimating Freshwater Needs to Meet Future Thermoelectric generation Requirement; DOE/NETL-400/2009/1339; U.S. Department of Energy, National Energy Technology Laboratory: Pittsburg, PA, USA, 2009. Available online: http://www.netl.doe.gov/research/ energy-analysis/publications/details?pub=dc6a8e2d-7b1e-4bc6-afa2-1c4a174f3615 (accessed on 10 February 2015).

20. Kinzelbach, W.K.H. Managing the cooling capacity of the upper Rhine: A case study. Environ. Manag. 1981, 5, 69-77.

21. Palaniappan, M.; Gleick, P.H.; Allen, L.; Cohen, M.J.; Christian-Smith, J.; Smith, C. Clearing the Waters, A Focus on Water Quality Solutions; United Nations Environment Programme \& Pacific Institute: Oakland, CA, USA, 2010. Available online: http:/www.unep.org/PDF/ Clearing_the_Waters.pdf(accessed on 14 August 2014).

22. Hnatiuc, E. Procedes Electriques de Mesure et de Traitement des Polluant (Electrical Methods for Measurement and Treatment of Pollutants); Editions TEC\&DOC, Lavoisier: Paris, France, 2002.

23. Brînduşa, A.; Kovacs, J. Thermoenergetic block on coal. Pollution vector: Burning gas. In Annals of the University of Petrosani; Universitas Publishing House: Petroşani, Romania, 2007; Volume 9, pp. 218-221.

24. Weil, J.C. A diagnosis of the asymmetry in top-down and bottom-up diffusion using a Lagrangian stochastic model. J. Atmos. Sci. 1990, 47, 501-515. 
25. Perry, S.G.; Burns, D.J.; Adams, L.H.; Paine, R.J.; Dennis, M.G.; Mills, M.T.; Strimaitis, D.G.; Yamartino, R.J.; Insley, E.M. User's Guide to the Complex Terrain Dispersion Model Plus Algorithms for Unstable Situations (CTDMPLUS); Volume 1: Model Description and User.110 Instructions; EPA/600/8-89/041; U.S. Environmental Protection Agency: Research Triangle Park, NC, USA, 1989.

26. Makinia, J. Mathematical Modelling and Computer Simulation of Activated Sludge Systems; IWA Publishing House: London, UK, 2010.

27. Tzolakis, G.; Papanikolaou, P.; Kolokotronis, D.; Samaras, N.; Tourlidakis, A.; Tomboulides, A. Emissions' reduction of a coal-fired power plant via reduction of consumption through simulation and optimization of its mathematical model. Oper. Res. J. 2010, 10, 71-89.

28. Breuil, J.M. Input-output analysis and pollutant emissions in France. Energy J. 1992, 13, $173-184$.

29. Institute of Power Engineering Studies (Institutul de Studii si Proiectari Energetice ISPE). Studiul Termic al Riului Jiu pe Sectorul amonte CTE Rovinari, Aval CTE Isalnita (Thermal Study of Jiu River on the Sector between Rovinari Power Plant Upstream and Isalnita Power Plant Downstream); Project 1073/8934/94; ISPE: Bucharest, Romania, 1994.

30. Bulucea, C.A.; Jeles, A.; Mastorakis, N.E.; Bulucea, C.A.; Brindusa, C. Managing through Pollutant Vector the Wastewater from a Chain of Coal-Fired Power Plants Discharging into Jiu River. In Recent Researches in Environment, Energy Planning and Pollution, Proceedings of the 5th WSEAS International Conference on Renewable Energy Sources (RES'11, EPESE'11, WWAI'11), Iasi, Romania, 1-3 July 2011; pp. 244-251.

31. Mastorakis, N.E.; Jeles, A.; Bulucea, Co.A.; Bulucea, Ca.A.; Brindusa, C. Evaluating the environmental impact of coal-fired power plants through wastewater pollutant vector. In Recent Researches in Geography, Geology, Energy, Environment and Biomedicine, Proceedings of the 4th WSEAS International Conference on EMESEG'11, Corfu Island, Greece, 14-16 July 2011; the 2nd International Conference on WORLD-GEO'11, Corfu Island, Greece, 14-16 July 2011; the 5th International Conference on EDEB'11, Corfu Island, Greece, 14-16 July 2011; pp. 181-187.

32. Bulucea, C.A.; Mastorakis, N.E.; Rosen, M.A.; Bulucea, C.A.; Jeles, A.C.; Brindusa, C. Assessing the Environmental Pollutant Vector of Wastewaters Discharged from a Chain of Coal-Fired Power Plants Along a River. Available online: http://sciforum.net/conference/wsf-4/paper/2475 (accessed on 12 May 2015).

33. Wu, F.H.Y.; Koh, R.C.Y. Mathematical Model for Multiple Cooling Power Plumes; Final Report of U.S. Environmental Protection Agency; Corvallis Environmental Research Laboratory: Corvallis, OR, USA, 1977; EPA Grant No. (5) R-803989-01-1. Available online: http://authors.library.caltech.edu/26006/1/KH_R_37.pdf (accessed on 16 April 2015).

34. Baumgartner, D.J.; Frick, W.E.; Roberts, P.J.W. Dilution Models for Effluent Discharges. Available online: http://water.epa.gov/scitech/swguidance/standards/upload/2007_01_17_ standards_mixingzone_RSB_UM_PLUMES.pdf (accessed on 10 January 2015).

(C) 2015 by the authors; licensee MDPI, Basel, Switzerland. This article is an open access article distributed under the terms and conditions of the Creative Commons Attribution license (http://creativecommons.org/licenses/by/4.0/). 